\title{
AOR
}

Selected Papers of \#AolR2021:

The 22nd Annual Conference of the

Association of Internet Researchers

Virtual Event / 13-16 Oct 2021

\section{ENTANGLED AUTONOMY ON AUTOMATED AIRWAVES: THE CASE OF RIVENDELL}

Andy Kelleher Stuhl

McGill University

Beginning in the early 2000s, a piece of software infrastructure for radio broadcasters brought several groups-distinguished by clashing stances on technology, communication, and cultural politics-into unlikely cooperation. The software, called Rivendell, is a free and open source radio automation system. In radio, automation refers to a set of utilities that allow stations to "stay on the air for hours with virtually no human intervention" (Douglas, 2004). In the latter decades of the 20th century, radio automation became an audible marker of rapid consolidation in American broadcast industries. Monopolistic firms bought up stations by the hundreds and, laying off local DJs, often used sophisticated automation suites to replace them with centrally and algorithmically managed content. When many independent broadcasters began adopting Rivendell after its first release in 2004, they were thus interfacing with an already controversial technological category among radio professionals: a type of tool that on one hand would allow a small group of volunteers to run a continually transmitting (or streaming) station and that, on the other, represented a technical facet of a corporatized upheaval to the whole medium. This paper treats Rivendell as an opening onto the politics at play when the liberal ethos propelling free and open source software ${ }^{1}$ meets the autonomy-prizing traditions of independent broadcasting at a juncture provided by automation.

Situating Rivendell in a longer history of media automation and the cultural contests that surround digital-era changes, I draw out a friction between discourses of autonomy and automatedness - the latter referring to media workers' critiques of automation's perceptible effects on the cultural institutions where it is installed. Elena Razlogova (2013) has shown how DJs at independent, freeform radio stations have worked out a nuanced relation to algorithmic audio tools: these radio workers tend to define their roles in contrast to but not necessarily in competition with music recommendation systems, while also relying on other software in producing their shows. But radio automation, since its origins in the 1950s, has been defined less by technological incursions from outside the medium than by concretizations of formatting - the same

\footnotetext{
${ }^{1}$ Coleman, Coding Freedom.

Suggested Citation (APA): Stuhl, A. K. (2021, October). Entangled Autonomy on Automated Airwaves: The Case of Rivendell. Paper presented at AoIR 2021: The 22nd Annual Conference of the Association of Internet Researchers. Virtual Event: AolR. Retrieved from http://spir.aoir.org.
} 
logic that "freeform" radio, in its name, opposes. The opposition between experimental and monopolistic poles of the radio industry spectrum is not, however, the only major tensions running through Rivendell. The development of this software, which quickly became a favored tool among left-leaning community stations, began within a right-wing Christian network.

Broadcast engineer Fred Gleason was working for Salem Radio Network, a national syndicator focused on Christian and conservative talk-format programming, when he began developing a new automation system that would meet the needs of his employer's affiliate stations at the start of the 2000s. In interviews with Gleason, I explore how and why this system, Rivendell, adopted a free and open source software (FOSS) architecture. This aspect of Rivendell, which along with Gleason has since split out from Salem, today distinguishes it in the radio automation field much more saliently than do its origins in a religious right context. Being open source means that current and past versions of Rivendell's C++ code and surrounding documentation can easily be retrieved, read, and executed. Analysis of this source code demonstrates how techniques and devices from early automation systems have persisted as structural metaphors in software. More significantly, though, my interviews and software analysis will examine how the tradition of right-wing Christian broadcasting interacted with these enduring radio automation structures and with the open source technologist ethos when all three combined in Rivendell's early development. By understanding how these elements came into articulation, I clarify what values Rivendell has carried forward in its ongoing use and maintenance-and what kinds of reconciliation have been required on the part of broadcasters in very different contexts who have used this automation software.

Automation and Christian conservatism have both been depicted as colonizing forces that have dominated and remade American radio. This paper explores movements that have levied such accusations, but it will foreground how ensuing efforts to radically reclaim radio have been entangled with those same forces. In 2008, low-power California station KDRT and the Prometheus Radio Project published a "Handbook on Automation" that detailed, among other things, how the station's operators relied on Rivendell since their launch in 2004 (just a year into the software's official release, while the project was still housed by Salem). Explaining automation to an audience of current or prospective grassroots broadcasters, the station engineers cite as one benefit of Rivendell that it can automatically retrieve and air new episodes of Democracy Now!, the daily progressive news show hosted by Amy Goodman. As Christina Dunbar-Hester (2014) recounts in her study of Prometheus, the left-leaning activists who pushed the federal government to make low-power FM licenses available entered an uneasy alliance with Christian groups interested in the same goal. The fact of that bygone alliance from a 2008 vantage point, after the FCC had acted upon that pressure, may explain why the political contrast between Salem's and KDRT's programming went unremarked in the handbook. Another tension is much more prevalent though: the opening pages acknowledge that "[s]ome people," and perhaps the majority of a station's volunteers, "might think radio automation is inherently evil" (Shaw, 2008). The work that played out within that Prometheus/KDRT handbook-making automation tools legible to an audience that may largely object to automation in principle-was not just parallel to the articulation that Dunbar-Hester describes; it was part of the same larger 
web of uncomfortable technical and political relations. Exploring how actors maintain a goal of autonomy amid these relations, this paper draws on an interview with Rivendell's lead developer, Fred Gleason. Gleason describes the user community as a "donut," noting that the large station conglomerates who occupy a central place in the current American radio landscape have no potential interest in the software because they built or acquired their own automation systems in the course of their expansion. This spatial metaphor invites us to look toward forms of relationality - a shared negative orientation toward a culturally, economically, and technologically dominant force-that may facilitate cooperation among groups in spite of their also desiring independence from one another.

\section{References}

Coleman, E. Gabriella. Coding Freedom: The Ethics and Aesthetics of Hacking. Princeton, NJ: Princeton University Press, 2013.

Douglas, Susan J. Listening in: Radio and the American Imagination. Minneapolis, MN: University of Minnesota Press, 2004.

Dunbar-Hester, Christina. Low Power to the People: Pirates, Protest, and Politics in FM Radio Activism. Cambridge, MA: MIT Press, 2014.

Razlogova, Elena. "The Past and Future of Music Listening: Between Freeform DJs and Recommendation Algorithms." In Radio's New Wave: Global Sound in the Digital Era, edited by Jason Loviglio and Michele Hilmes, 62-76. New York, NY: Routledge, 2013.

Shaw, Jeff. "Handbook on Radio Automation." Philadelphia, PA: Prometheus Radio Project, 2008. 